\title{
Editorial Volume 3 (2)
}

\section{Introduction}

We are pleased to present the sixth issue of Exchanges: the Warwick Research Journal. This issue completes the third volume of the journal and continues to promote exciting interdisciplinary research and scholarship from researchers at all stages of their careers.

Every year Exchanges continues to grow in reputation as an open access, peer-reviewed, interdisciplinary journal. This is evidenced by the large number of high-quality submissions we continue to attract. This issue includes articles from a range of disciplines, including Classics and Ancient History, French Literature, English and Comparative Literature, Translations Studies, Linguistics, Sociology, Politics and International Relations, and Chemistry. All of the articles published in this edition highlight the importance of breaking down traditional disciplinary boundaries; some particularly focus on interdisciplinarity, such as the review article 'Anorexia and Its Metaphor' (Medical Humanities) and the two critical reflection pieces, 'Translation and Modernism: Mapping the Relationship' (English, French, German, Translation Studies, and Cultural Studies) and 'Exploring the Interconnection between Culture and Behaviour' (Linguistics, Psychology, and Cultural Studies). We hope that the submissions in this edition of the journal will offer productive exchanges between different academic disciplines.

\section{Exchange, debate, and dialogue}

Exchanges always strives to promote dialogue and debate through the articles and pieces it publishes. In this insightful conversation piece, Ali Saqer, who has recently completed his doctorate from the Department of Politics and International Studies (PaIS) at the University of Warwick, discusses the Eurozone crisis and the challenges for the future of Europe with Professor Alex Callinicos. Professor Callinicos is a renowned social theorist and scholar of international political economy at King's College London, well known for his political activism. Focusing on Greece, Professor Callinicos notes that the Eurozone crisis, far from being only a financial crisis, has had significant political implications, particularly with regard to European integration. This discussion is all the more topical in the light of the ongoing refugee crisis, the imminent EU referendum in the UK, and the continued political and economic challenges that Greece faces. One of the highlights of this interview is how Professor Callinicos 
relates the political situation of Greece to that of Britain; he suggests that left-wing ideas, specifically 'a socialist planned economy' (150), may offer a solution, although he acknowledges the difficulties in their implementation.

\section{Featured section: 'Sensory Experience in Ancient Rome'}

This issue offers a featured section by two researchers from the Department of Classics and Ancient History at Warwick: Joanna Kemp and Ghislaine van der Ploeg. Both authors explore the senses in Ancient Rome.

Joanna Kemp examines the Sebasteion in Aphrodisias and its political and ideological messages. Departing from previous studies of this monument, which primarily focus on visual details, Kemp notes the different experience of the contemporary spectators during a religious procession. In ancient Rome, movement was therefore essential to one's sensory experience of architecture. Such experience was taken into consideration by the architects of religious complexes, who employed techniques, repetition for example, to guide the moving spectators and convey a strong message of empire.

Ghislaine van der Ploeg examines the multi-sensory impact of an imperial visit to a sanctuary, Caracalla's Supplication at the Pergamene Asclepieion in this case. Studying the medallions of that time which depicted the event, particularly the emperor's movement from secular to sacred spaces, Van der Ploeg investigates the relations between the imperial and the divine. To eternalise and monumentalize the adventus and the emperor, these images are, however, manipulated: the senses of the viewers are deliberately removed.

\section{Feminism, postcolonialism, and intersection}

The one remaining article and two review articles published in this issue reflect the strong interests in feminism and postcolonialism shared by many disciplines ranging from literature to sociology.

In her study of Nancy Huston's The Goldberg Variations and Slow Emergencies, Polly Galis demonstrates how Huston avoids an imperial representation of others and challenges the boundaries between such categories of being such as class, race, and gender by speaking to rather than for others. Drawing on both postcolonial and feminist theories, the article examines the intersection between the two strands in Huston's 
fiction and argues that both novels offer an intersectional view of identity and otherness.

Both of the review articles focus on the female body. Drawing on Sontag's 'illness as metaphor', Susannah Wilson considers anorexia and its metaphors in her review of key publications, contemporary press reports, and historical research on anorexia. Wilson observes that the popular beliefs, or myths, surrounding this eating disorder are culturally constructed through metaphorical thinking, and, therefore, she suggests that such metaphors should be broken down to allow a better understanding of anorexia.

Reviewing Nisha Pahuja's 2012 documentary film The World before Her, Saba Hussain and Nazia Hussein's co-authored article reflects on the appropriation of women's bodies and subjectivities by neoliberal governmentality in the Miss India contest and the Hindu militant Durga Vahini camp. Hussain and Hussein consider both neoliberal capitalism and religious fundamentalism to establish a link between these two ideologies, which are often discussed separately in terms of their oppressions of women. Although their bodies are made to serve different ideologies in a similar way, some women manage to negotiate their agency within such power structures.

\section{Cutting-edge research, interdisciplinarity, and innovation}

The four critical reflection pieces in this issue cover a variety of interesting topics; all highlight the cutting-edge research in their fields and illustrates how interdisciplinary research not only connects different academic fields but also energises each by raising new questions, breaking new grounds, and showing new directions.

Joanna Rzepa, an Early Career Fellow at the IAS, University of Warwick, reflects on a conference which she organised in January 2016 here at Warwick, which explored the emerging interdisciplinary field of modernism and translation. The conference created dialogue and debate among researchers from a variety of disciplines ranging from translation studies, comparative literature, modernist studies, English studies, and modern languages. Noting the great potential of a study of the relation between translation and modernism in twentieth-century literary culture, Rzepa points out the ways in which this new research area can be further pursued.

There is another critical reflection piece on an interdisciplinary conference: Carolin Debray, Thomas Greenaway, and Kyoungmi Kim, the organisers of the 'Interconnections between Culture and Behaviour' 
conference, review their event. The conference promoted discussion and the exchanges of ideas between disparate disciplines in order to progress conceptual and methodological approaches to understanding culture and behaviour. Renowned researchers from psychology, sociology, and applied linguistics presented in a panel of two speakers, outlining their perspectives on the topic. During table discussions, speakers and participants focused on the compatibility of different approaches. The organisers reflect on the insights gained in relation to wider questions that inspired the conference, research recommendations, the challenges of interdisciplinary research on such a complex topic, and the potential of collaboration as a solution.

Katja Laug organised a workshop which was dedicated to Cormac McCarthy's 1985 novel, Blood Meridian. The event attracted both the established and the younger generation of McCarthy scholars. Thanks to live streaming and recording, the discussion was made available to a wider, international audience outside the academia. Warwick is renowned for its innovative teaching, promoted particularly by the Institute of Advanced Teaching and Learning (IATL); as Laug's workshop shows, technology enhances not only teaching and learning but also the dissemination of research and public engagement. As an emerging interdisciplinary research area, digital humanities is attracting increasing attention.

Alex Marsden, an Early Career Fellow at the IAS, University of Warwick, reviews the Materials Week, held at Warwick in early February. In his engaging piece, Marsden focuses on the emerging field of twodimensional materials. A highlight of the Materials Week was the talk given by Professor Sir Konstantin Novoselov, one of the two Nobel Prize winners in Physics for their discovery of the 2-D material graphene. Professor Novoselov emphasised in his talk that although graphene is the most well-known, there is a family of 2-D materials. He, therefore, suggested that the entire collection should be explored, layering different 2-D materials for example. Marsden illustrates the significance of communicating cutting-edge scientific research to a wider audience: to researchers in other academic fields who seek interdisciplinary collaboration and to the public who would like to better understand how research transforms the world around them.

\section{Thanks}

Many thanks for your continued support of the journal through your readership and engagement with our articles. Readers play an important part in the life of the journal and we encourage you to share, comment 
on, enter into discussion and ask questions about our articles and critical reflections. We hope you find this issue as stimulating and thoughtprovoking as we have, and hope that you enjoy reading pieces outside of your research specialisms.

Finally, we want to thank all of the peer reviewers who generously volunteered their time to read each of our submissions carefully and provided helpful, constructive feedback for our authors. We are truly grateful to Yvonne Budden, Scholarly Communications Manager, University of Warwick, for her continued support and assistance with the development of the journal. Special thanks are reserved for former Senior Editors Naomi Pullin and Karen Simececk for their guidance and support and also their promotion of the journal.

We look forward to the next issue, which will be published in October 2016 and will feature an interview with Professor Martin Stannard, the biographer of Evelyn Waugh and the Principal Investigator and CoExecutive Editor of OUP's 42-volume scholarly edition of The Complete Works of Evelyn Waugh.

The Editors

Yuexi Liu (Senior Editor) / English

Harbir Bal / Centre for Education Studies

Nof Nasser Eddin / Sociology

Misato Matsuoka / Politics and International Studies

Naomi Pullin / History

Daniel Silva / Politics and International Studies 